\section{Enzyme motifs in antibodies}

SIR-The promise of protein crystallography for understanding the structural basis for enzyme mechanisms is being realized, in part, by the growing recognition of a few basic catalytic motifs. Examples include the structurally related Asp-His-Ser and Asp-His-Zn catalytic triads, recently discussed in News and Views $^{1}$ and in Scientific Correspondence ${ }^{2}$.

Conventional studies of enzyme active sites use site-directed mutagenesis to probe the chemical function of amino-acid residues. We have developed a complementary approach involving transplantation of catalytic motifs into antibodycombining sites which should clarify the function of residues in enzyme catalytic motifs and improve the design of catalytic antibodies by allowing the addition of appropriate residues and metal cofactors.

Although other proteins with catalytic sites have been designed de novo, such as a helix bundle with serine protease activity, the use of antibodies has several advantages. First, the structure of the antibody framework is strongly conserved, providing a well-defined protein backbone. Second, portions of the complementaritydetermining regions are strongly structurally conserved but allow for sequence variability ${ }^{4}$, so catalytic models can be built in a predictable manner. Third, the

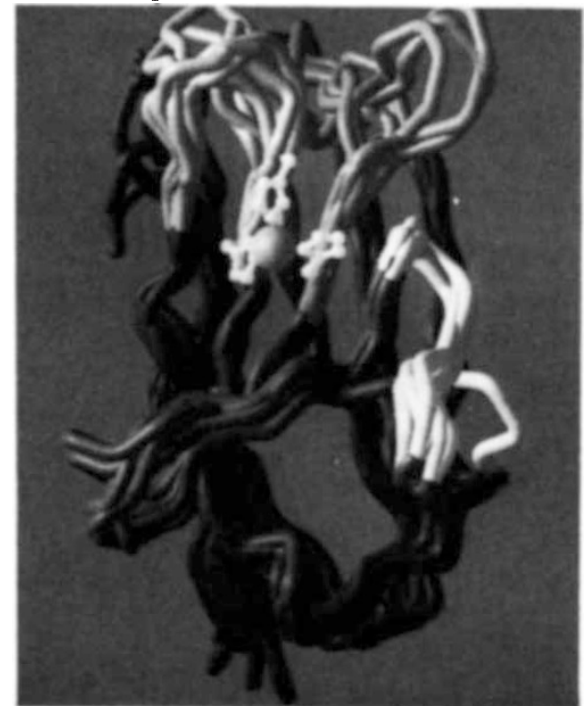

Transplantation of a cofactor-binding site into the antibody light-chain complementaritydetermining regions (CDRs). The framework Fv regions (dark grey) for the antibodies McPC603, D1.3, HyHEL5, HEd10, Newm, Kol, J539, 4-4-20 and R19.9 are superimposed to show the $\mathrm{C}_{\text {, }}$ backbones of the light-chain variable region (CDR1, medium grey; CDR2, white; and CDR3, light grey) with the zinc site from carbonic anhydrase (three histidines and the zinc atom) superimposed onto residues 34 , 89 and 91 . Binding site (top) faces forward. Although the CDRs show much more structural variation than the framework regions, all the antibodies share the $\beta$-strand structure that extends from the framework into the CDRs. antibody sequence can be varied in these structurally conserved regions to test the specific requirements of the environment surrounding the catalytic motif. Fourth, the immune system can be used to create antibodies with appropriate binding sites for a given antigen. Finally, as techniques are now available for the combination of separate light- and heavy-chain libraries, chains with different binding specificities can be matched to complementary chains with different catalytic motifs.

Structural templates can be recognized, dissected from their environment in the enzyme and transplanted into any of a set of general sites within the antibodycombining site ${ }^{+}$where their resulting metal binding or catalytic activity can be tested outside the original enzyme. Because these general sites are in the structurally conserved, sequence variable areas of complementarity-determining regions, this transplantation process is likely to be applicable to all antibodies.

An example of a structural template is the three-dimensional pattern of catalytic zinc sites, which include a main-chain hydrogen bond joining two of the zinc ligands ${ }^{4}$. The template for carbonic anhydrase, in which the three zinc ligands lie on two hydrogen-bonded antiparallel $\beta$-strands, can be accommodated in five structurally conserved sites general to all known antibody structures ${ }^{4}$. For one such antibody light-chain general site, the replacement of three amino acids in the complementarity-determining regions with histidine residues formed a zincbinding site with an open coordination position at the bottom of the antigenbinding pocket (see figure). Creation of this site in the anti-fluorescein antibody 4-4-20 gave a mutant antibody that binds copper, zinc and cadmium with the same preferences as carbonic anhydrase

Thus, multisite design based on structural templates can be used to remodel an antibody to contain a cofactor-binding site, without requiring further mutagenesis and screening. Our new approach for designed antibody mutants could be used to evaluate features such as the Asp-His linkage in Asp-His-Zn and Asp-His-Ser catalytic triads independent of other features in the evolved enzyme active site.

JOHN A. TAINER

VICTORIAA. ROBERTS

Department of Molecular Biology,

Research Institute of Scripps Clinic,

La Jolla, California 92037, USA

1. Blow, D. Nature 343, 694-695 (1990)

Christianson, D. W. \& Alexander, R S, Nature 346, 225 (1990).

Hahn, K. W., Klis, W. A. \& Stewart, J. M. Science 248. 1544-1547 (1990).

Roberts, V.A. et al. Proc. Natn. Acad. Sci. U.S.A. 87 $6654-6658(1990)$

Iverson, B L et al Science 249 659-662 (1990).

\section{Alcohol sensitivity}

SIR - Luddens et al. , in their paper ${ }^{1}$ on the importance of the $\alpha 6$ subunit in the binding of the benzodiazapine Ro15-4513 to a subtype of the $\mathrm{GABA}_{\mathrm{A}}$ receptor, stated: "most importantly, the newly characterized $\mathrm{GABA}_{\mathrm{A}}$ receptor seems to be functionally involved in mediating the alcoholinduced impairment in motor performance that can be antagonized at the same receptor by Ro15-4513". Because the authors found this subunit only in cerebellar granule cells, their conclusion is not consistent with the fact that the authors of the original study showing antagonism of ethanol on $\mathrm{GABA}_{\mathrm{A}}$ receptors by Ro15-4513 (ref. 18 in ref. 1) used rat cortex, a tissue that does not contain the a6 subunit. Furthermore, we have shown that Ro15-4513 is equally effective as an ethanol antagonist with $\mathrm{GABA}_{+}$receptors from cortex or cerebellum.

In the cerebellum, ethanol-induced motor impairment is genetically linked with the action of ethanol on Purkinje cells (which do not contain the new receptor) (3-5 $^{3-5}$ This action is antagonized by R015-4513 (ref. 6). It is possible that the $\alpha 6$ subunit is expressed in other brain regions and cell types and that the techniques used by Luddens et al. were not sufficiently sensitive to detect this expression, or that it is developmentally regulated (the authors did not specify the age of the rats used) - but these hypotheses remain untested.

Finally, although the Ro15-4513binding site does differ in one pair of lines (AT) ANT) selected for ethanol sensitivity (ref. 17 in ref. 1), no differences were detected in this site in eight other lines (LS/SS, HAS/ LAS, FAST/SLOW, HOT/COLD) selected for alcohol sensitivity (E. R. Korpi, personal communication), although differences in ethanol sensitivity of the GABA receptor have been shown for several of these lines ${ }^{7 . *}$. Thus, the difference in receptors between $\mathrm{AT} / \mathrm{ANT}$ rats may result from gene fixation during inbreeding and may be unrelated to alcohol sensivity. In view of these data, it seems premature to attempt to link the $\alpha 6$ subunit to alcohol sensitivity.

Department of Pharmacology,

4200 East Ninth Ave,

Denver,

Colorado 80262, USA

Luddens, $H$., Pritchett, D.B., Köhler, M. Killisch, Keinänen, K., Monyer. H. Sprengel, R. \& Seeburg, P.H Nature 346.648-651 (1990)

. Harris, R.A., Allan, A.M., Daniell, L.C. \& Nixon, C. J. phar mac. Exp. Ther. 247, 1012-1017 (1988)

Sorensen, S. Palmer, M Dunwiddie, T \& Hoffer, B. Science 210, 1143-1145 (1980).

Spunler, K Hoffer, B. Weiner, N. \& Palmer, M. Pharmac. biochem. Behav, 17, 569-578(1982).

Palmer, M.R., Wang, Y.. Fossom, L.H. \& Spuhler, K.P. Alc Clin. exp. Res. 11, 494-501 (1987).

6. Palmer, M.R., van Horne, C.G., Harlan, J.T. \& Moore, E.A. J. pharmac. Exp. Ther. 247, 1018-1024 (1988)

Harris, R.A. \& Allan, A.M. FASEB J. 3, 1689 (1989)

8. Wafford, K.A., Burnett, D.M., Dunwiddie, T.V. \& Harris, R.A. Science 249, 291-293 (1990). 